\title{
The Benefits and Barriers Related to Regular Participation in Physical Activity by African-American Women: Implications for Intervention Development
}

\author{
Meredith S. Scott, Roy F. Oman, Robert John \\ Department of Health Promotion Sciences, University of Oklahoma Health Sciences Center, Oklahoma City, \\ USA \\ Email: Meredith-Scott@ouhsc.edu
}

Received 2 March 2015; accepted 11 April 2015; published 16 April 2015

Copyright (C) 2015 by authors and Scientific Research Publishing Inc.

This work is licensed under the Creative Commons Attribution International License (CC BY). http://creativecommons.org/licenses/by/4.0/

(c) (i) Open Access

\section{Abstract}

A common strategy for improving health behaviors is to emphasize the benefits and reduce the barriers to behavior change. This study investigated potential differences in perceived benefits and barriers related to participation in physical activity (PA) between women in pre-maintenance versus the maintenance phase of $P A$ behavior to determine if perceived benefits were greater and perceived barriers lower in women with more extensive and successful PA participation experience. Data were collected from a community-based sample $(N=113)$ of middle-aged AfricanAmerican women. The sample was stratified into two groups according to how long they had been regularly engaging in PA (6 months or longer versus less than 6 months). Chi-square analyses were conducted to investigate possible differences between the two groups of women in regard to perceived benefits and barriers associated with PA. Descriptive data showed that nearly all of the benefits and barriers to PA were perceived as being important for a majority of the participants and chi-square and t-test results indicated few significant between-group differences $(p<.05)$ in regard to these perceptions. Additional analyses indicated there was no significant betweengroup difference $(p<.05)$ for Body Mass Index. The results suggest the benefits and barriers related to PA behavior are already valued and understood by many African-American women. Further, the results do not support the commonly held belief that effective health behavior improvement programming should emphasize the benefits and reduce the barriers related to the behavior. Practitioners should consider focusing on other evidenced based factors proven to promote PA behavior such as counseling regarding social support (e.g., buddy system) and increasing self-efficacy (e.g., goal setting) to initiate and sustain a physically active lifestyle. 


\section{Keywords}

\section{Physical Activity Behavior, African American Women, Benefits and Barriers, Maintenance of Physical Activity Behavior, Initiation of Physical Activity Behavior, Transtheoretical Model}

\section{Introduction}

A majority of the population remains insufficiently active despite the well-known health benefits of regular participation in physical activity (PA) and despite decades of research investigating factors associated with PA [1]. African American women in particular consistently report being less physically active than others and are disproportionally affected by chronic disease and poor health outcomes [2] [3]. Several studies have examined correlates of physical activity in African American women and have reported that factors such as perceived health, social support, self-efficacy, and neighborhood safety were related to participation in PA [4]-[7].

Barriers (e.g., competing responsibilities, safety, lack of facilities) and benefits (e.g., improved health, stress relief, enjoyment) related to engaging in PA behaviors are central components of several individual theories of behavior change (e.g., Health Belief Model) and are often the focus of interventions [8] [9]. An important variable that may affect the salience of benefits and barriers to PA behavior is the individual's stage of behavioral change. The stages of behavioral change are a central component of the Transtheoretical Model (TTM) in which individuals are believed to change their behaviors by progressing through a series of stages ranging pre-contemplation to maintenance of the behavior [10] [11].

In the application of the TTM to PA behavior, it is believed that factors related to initiation of a PA program are often different than factors related to long-term participation in a PA program [12] [13]. For example, individuals may begin a PA program for the benefit of improved health but over time they may adhere to the program because of social support received from individuals in the PA program. Thus, in this example, the benefit of health improvement may be a salient factor leading to the initiation of PA; however, social support emerges as a more important factor that leads to long-term participation in PA.

Perceptions of barriers may change as well. It is believed that barriers must be overcome in order for an individual to become a regular participant in PA [12] [13]. Therefore, the barriers to regular participation in PA may be significant obstacles to address for individuals initiating a PA program but less of a concern for those in the maintenance stage. In summary, the perceived importance of specific benefits of PA as well as barriers to regular PA could be expected to substantially change as individuals progress through the stages of PA behavior change [12] [13].

Barriers to regular participation in PA as well as the benefits of PA have been identified as factors associated with PA behavior in qualitative studies of African American women [6] [7] [14] [15]. However, quantitative research involving various segments of the population has reported conflicting results with some studies finding significant associations between barriers and benefits related to PA [11] [16] [17] and other studies reporting no significant associations between the variables and PA behavior [18] [19].

For example, a study of African-American women attending college found the perceived barriers of PA, but not the perceive benefits, were significantly different across the stages of change [16]. In a study of white lower and middle-income women, Marcus and Owen [11] found that the importance of benefits and barriers related to PA were significantly different across the stages of change. Similar results were reported by Marcus et al. [17] in two studies involving middle age women and men. Conversely, in a sample of older men with heart disease, researchers found that benefits and barriers related to PA did not differentiate between those who maintained a PA program and those who did not [18]. Finally, in a study of women (race/ethnicity not identified) attending college, Taggart et al. [19] reported no significant associations between PA behavior and either benefits or barriers. These mixed results suggest that other factors may influence associations between benefits and barriers and PA behavior. In addition, the literature review indicates that additional quantitative research investigating the PA behavior of African American women is warranted as there are few published studies in this area.

The notion that the influence of PA-related variables may change as individuals progress from initiating to maintaining a PA program also pertains to an interesting phenomenon observed among African American women and reported in the PA behavior literature [7] [15]. Research has suggested that some African American 
women believe they could be both fit and overweight and that their weight status was not an important benefit gained from participation in PA [7] [15]. Thus, viewed through this perspective, one could be in the maintenance stage of PA behavior but still be overweight or obese. Focus group results involving African American women indicated that body weight and PA behavior are generally viewed as separate unrelated issues [7] [15]. Data collected in this study allows further investigation of this issue through analyses of Body Mass Index (BMI) (as a potential benefit of PA) and possible associations with the stages of PA behavior change.

Individuals who successfully initiate and maintain a PA program are a minority of the population as suggested by statistics indicating that approximately $50 \%$ of individuals who begin a PA program relapse to sedentary behavior before six months [20]. Therefore, factors associated with PA behavior may be different for neophyte versus seasoned PA participants as suggested by the Transtheoretical Model [10] [11]. Neophyte PA participants are in one of the four early stages of behavior change whereas seasoned PA participants are in the fifth stage (maintenance stage) of PA behavior as indicated by the by the Transtheoretical Model [10] [11] The purpose of this study was to examine possible differences in the perceptions of the barriers and benefits of participation in regular PA among African American women who were in the maintenance stage of PA behavior versus African American women who were in the earlier stages of PA behavior [10] [11]. A secondary purpose was to examine possible differences in BMI (as a potential benefit of PA) between the two groups of women.

\section{Methods}

\subsection{Design}

The study was approved by the Institutional Review Board and every participant was consented into the study. Study data were collected in September and October of 2011. Data were stratified to compare participants who had engaged in regular PA for at least 6 months (maintenance stage, $n=42$ ) to those who were inactive or active but for less than 6 months (pre-maintenance stages, $\mathrm{n}=71$ ) (Table 1 ).

\subsection{Participants}

Researchers partnered with a predominantly African American organization, Sisters in Motion, to recruit a community-based sample of female participants for the study. Data were collected at three free public events sponsored by Sisters in Motion that focused on women's health and wellness and included a physical activity component. A substantial majority ( $>90 \%$ ) of the attendees participated in the study; however, it was not possible to determine a precise response rate because of the nature of the events that were designed for community involvement rather than research. The questionnaire was completed by 128 female participants of whom 113 were African American women. These women served as the study population.

\subsection{Measures}

The survey was self-administered using standard paper and pencil data collection methods. Questions were written using common terms and were designed for individuals with at least 8th grade English reading skills.

BMI. Body mass index (BMI) was calculated using self-reported height and weight data from the questionnaire. The formula was weight (pounds) $\times 703 /$ height (inches) [21]

Health Status. Health status was assessed by a single item, "How would you rate your current overall physical health?” Possible responses were "excellent”, “good”, “fair”, or “poor”. The item was adapted from similar measures commonly used in the field and has been validated in morbidly and mortality studies [22] [23].

Smoking Status. Smoking status was assessed using the item, "How often do you smoke cigarettes? Possible responses were "every day", "some days", or "not at all”. Participants who responded "every day" and "some days" were classified as smokers. The smoking status item was adapted from the Behavioral Risk Factor Surveillance System Questionnaire administered annually by the Centers for Disease Control and Prevention [24] [25].

Perceived Benefits and Barriers Related to Participation in PA. The items assessing perceived benefits and barriers to PA were developed using data from six focus group discussions among low-income and minority women that were conducted prior to the current study. Eleven benefits and six barriers were identified (Table 2). On the survey, participants were asked to indicate the importance of each perceived benefit and barrier ranging from "very important", "neutral”, or "not important". The "neutral” and "not important" responses were com- 
bined to contrast with the "very important" responses. The barriers and benefits items were identified following recommendations that elicitation research (e.g., focus groups) should be conducted to identify items salient to the population prior to using the measures in outcome studies [26]. The Cronbach's alpha for the barriers as well as the benefits scale was 0.70 .

Stages of Change. The participants' current stage of PA behavior was assessed using standard stage of change classification items [10] [27]. The participants were asked to select the item that best described their current PA behavior. The stages of change were: 1) "I am not physically active now, and do not plan to be physically active"; 2) "I am not physically active, but I am thinking about becoming physically active"; 3) "I am currently making an effort to start being physically active (e.g., joining a fitness group)"; 4) "I just started being physically active within the past 3 months"; and 5) "I have been physically active regularly for more than 6 months". The 5 items represent pre-contemplation, contemplation, preparation, action, and maintenance stages, respectively, of the Transtheoretical Model [10]. Marcus et al. [27] reported a kappa index of 0.78 indicating adequate reliability for the measure.

\subsection{Statistical Analyses}

Data from participants in the pre-contemplation through actions stages were combined to contrast with data from participants in the maintenance stage. Data analysis was conducted using IBM SPSS version 18. Chi-square and t-tests were conducted to examine possible differences between the pre-maintenance and maintenance groups in regard to demographic, general health, BMI, and barriers and benefits data. The exact method (2-tail) was used to determine precise significance levels for the chi-square analyses of the benefits and barriers data and a Bonferroni correction was made to the $p$ value to reduce the likelihood of making a type I error [28].

\section{Results}

\subsection{Descriptive Statistics}

The participants were 113 African American women (mean age $=51.3$ years, $S D=14.2 ; 62 \%$ employed full time; $54 \%$ graduated college; $30 \%$ married; Mean BMI $=29.9, S D=6.6)$. Participants indicated their stages of PA behavior change as follows: pre-contemplation $(n=6)$, contemplation $(n=19)$, preparation $(n=26)$, action $(n=20)$, and maintenance stages $(n=42)$. As shown in Table 1 , there were two significant differences between the pre-maintenance and maintenance groups. Women in the maintenance group were significantly more likely $(p=0.004)$ to indicate their health was excellent or very good and less likely to indicate their health was fair or poor compared to women in the pre-maintenance group. Also, women in the maintenance group were significantly less likely $(p=0.018)$ to smoke. These results suggest the two groups of women were generally more similar than different in regard to demographic and basic health data.

Data in Table 2 show that nearly all of the benefits and barriers were perceived as very important for $50 \%$ or more of the participants suggesting these variables were salient factors related to PA participation for women in both the pre-maintenance and maintenance groups. The only barrier that was not endorsed by a majority was the need for childcare, possibly because of the age composition of the sample.

Table 2 documents that the percentages for the perceived benefits were typically higher compared to the percentages for the perceived barriers suggesting that perceived benefits were collectively appraised as more important than perceived barriers. The benefits most frequently cited as very important were that participation in PA improves quality of life, decreases stress, increases energy, and reduces the risk of premature death. The barriers related to PA most frequently cited as being very important were lack of knowledge of exercise techniques, an unsafe environment, and lack of time.

\subsection{Comparing Perceptions of Women in Pre-Maintenance Stages to Maintenance Stage of PA}

Of 17 possible differences between the pre-maintenance and maintenance groups in regard to perceived benefits and barriers related to PA, there was just two significant $(p<.05)$ between-group differences (Table 2). Participants in the maintenance group were more likely to cite stress reduction as a benefit of PA although both groups indicated it was important. Interestingly, participants in the maintenance group also were significantly $(p<.05)$ more likely to cite lack of access to a gym as a barrier to PA. These results indicate the pre-maintenance and maintenance groups of African-American women were much more similar than different in regard to the perceived benefits and barriers to 
Table 1. Descriptive statistics of participants in the pre maintenance stages and maintenance stage of physical activity behavior.

\begin{tabular}{|c|c|c|}
\hline & Pre maintenance (\%) $\mathrm{N}=71$ & Maintenance (\%) $\mathrm{N}=42$ \\
\hline \multicolumn{3}{|l|}{ Marital status } \\
\hline Married & 31 & 26 \\
\hline Never married & 23 & 26 \\
\hline Separated/Divorced/Widowed & 43 & 41 \\
\hline Live with partner & 3 & 3 \\
\hline \multicolumn{3}{|l|}{ Education level } \\
\hline Grade school/Some high school & 3 & 5 \\
\hline High school graduate & 11 & 2 \\
\hline Vo-Tech & 3 & 5 \\
\hline Some colleges & 33 & 29 \\
\hline College graduate & 50 & 59 \\
\hline \multicolumn{3}{|l|}{ Employment status } \\
\hline Full time & 65 & 60 \\
\hline Part time & 7 & 7 \\
\hline Unemployed & 10 & 10 \\
\hline Home maker & 4 & 2 \\
\hline Retired & 14 & 21 \\
\hline \multicolumn{3}{|l|}{ Current physical health ${ }^{*}$} \\
\hline Excellent & 0 & 10 \\
\hline Good & 62 & 76 \\
\hline Fair & 34 & 14 \\
\hline Poor & 4 & 0 \\
\hline \multicolumn{3}{|l|}{ Smoking status $^{* *}$} \\
\hline Non-smoker & 83 & 98 \\
\hline Smoker & 17 & 2 \\
\hline Age, years (SD) & $50.3(13.0)$ & $52.2(15.7)$ \\
\hline
\end{tabular}

*Significant $(p=.004)$ between-group difference; ${ }^{* *}$ Significant $(p=.018)$ between-group difference.

Table 2. Comparison of participants in the pre maintenance stages to the maintenance stage of physical activity behavior.

\begin{tabular}{|c|c|c|}
\hline & Pre maintenance (\%) $\mathrm{N}=71$ & Maintenance (\%) $\mathrm{N}=42$ \\
\hline \multicolumn{3}{|l|}{ Benefits (\% indicating "very important") } \\
\hline Increase my endurance & 94 & 90 \\
\hline Weight management & 89 & 93 \\
\hline Feel more confident & 77 & 81 \\
\hline Increases my quality of life & 97 & 100 \\
\hline Sleep better & 80 & 83 \\
\hline Helps me manage a chronic disease & 82 & 84 \\
\hline Decreases stress ${ }^{*}$ & 89 & 100 \\
\hline Increases energy & 94 & 95 \\
\hline Gets me out of the house & 62 & 65 \\
\hline Reduces risk of dying early & 93 & 93 \\
\hline Staying active with my family & 88 & 80 \\
\hline \multicolumn{3}{|l|}{ Barriers (\% indicating "very important") } \\
\hline Unsafe environment & 79 & 74 \\
\hline No one to do it with me & 69 & 71 \\
\hline Not enough time & 71 & 70 \\
\hline Lack of access to a gym ${ }^{* *}$ & 50 & 71 \\
\hline Do not know exercise techniques & 81 & 87 \\
\hline Lack of childcare & 25 & 24 \\
\hline BMI $(S D)$ & $30.5(7.0)$ & $29.1(5.9)$ \\
\hline
\end{tabular}

*Significant $(p=.025)$ between-group difference as indicated by chi-square test. ${ }^{* *}$ Significant $(p=.036)$ between group difference as indicated by chi-square test. 
PA. The mean BMI scores placed both groups of women in the overweight or obese category and there was no significant between-group difference for BMI.

\subsection{Post-Hoc Analyses}

Additional analyses were conducted to determine if smoking and health status influenced the results because there were significant between-group differences for the two variables. Data for smokers $(n=13)$ and women reporting poor health $(n=3)$ were removed from the database and the analyses comparing the pre-maintenance to maintenance groups in regard to perceived benefits and barriers related to PA were repeated. Excluding smokers resulted in a non significant $(p=.079)$ between-group result for the PA benefit of decreased stress. Excluding women who reported poor health did not change the results. The statistical significance for all other comparisons did not change. The post-hoc analysis reveals that if smokers are excluded from consideration, there were no significant between-group differences in regard to the perceived benefits and barriers related to PA which further supports the main findings that African American women in the maintenance versus pre maintenance stages of PA are much more similar than different in regard to the importance of the perceived benefits and barriers to participation in PA.

\section{Discussion}

This study examined perceived benefits and barriers related to PA behavior in a community-based sample of middle-aged African American women for the purpose of exploring potential differences between individuals in the pre-maintenance versus maintenance stage of PA behavior. The results indicated that the benefits and barriers related to participation in PA were perceived as very important for the majority of the participants and that there were few differences between the two groups of women in regard to these perceptions. There were no significant differences between the pre-maintenance and maintenance groups for 10 of the 11 perceived benefits and 5 of the 6 perceived barriers. Interestingly, BMI was also not significantly different between the two groups of women.

Research investigating the benefits and barriers related to participation in PA has reported mixed findings in study samples that included African American women and other segments of the population [11] [16]-[19]. Nonetheless, the lack of significant differences in the perceptions of the two groups of women was somewhat surprising because of the intuitive notion that perceived benefits and barriers related to PA should differentiate neophyte and experienced PA participants. Perhaps there were few differences in this specific study population because women self-selected into the community event and already had considerable knowledge and interest in women's wellness and health issues regardless of their PA experience. Alternatively, it could be that the benefits and barriers related to PA participation generally do not vary across African American women's stage of PA behavior change; this conclusion would be in partial or complete agreement with research conducted by Taggart and Connor [19], Juniper et al. [16], and Oldridge and Streiner [18] that involved African American women among other populations.

Interestingly, one of the two significant differences was in the opposite direction than what might be expected. Compared to women in the pre-maintenance group, women in the maintenance group were more likely (71\% versus 50\%) to indicate that lack of access to a gym was a barrier to PA. In addition to indicating that this barrier had not prohibited experienced PA participants from being active, the findings suggest that lack of gym access was not perceived as a barrier by more pre-maintenance women because they did not have enough experience yet to identify it as a barrier.

The results also contribute to research suggesting that some African American women place less emphasis on reduced body weight as an anticipated or desired outcome of regular participation in PA [7] [15]. In this study both groups placed considerable importance on weight management as a benefit of PA and there was no significant between-group difference in regard to the importance of this perceived benefit. However, the mean BMI for both groups was near the cut-off between overweight and obese and there was also no significant difference in BMI for the two groups. The results suggest that although weight loss was a perceived important benefit of PA, in actuality, it was not a realized benefit even by those women who had been participating in regular PA for 6 months or longer. Yet, the apparent failure of regular participation in PA to manage weight had not deterred the women from continuing to be active. These results agree with previous qualitative research findings that being physically active is not just about weight loss for African-American women [7] [15]. Furthermore, there is 
growing clinical evidence that regular participation in PA results in health benefits (e.g., cardiometabolic risk profile) that are independent of weight loss [29]-[32]. Thus, when providing counseling regarding participation in PA it is important to emphasize that, although weight loss is a desirable goal and a benefit of PA, it should not be considered as the only meaningful outcome or perhaps even the most significant health-related outcome.

Limitations of the study include that all data were self-reported. However, there is no reason to believe that potential issues with the self-report data would be more prevalent in one group of the women compared to the other and thus influence the results. A second limitation is that the PA history of the women was not assessed. Because this information was unknown, substantial previous PA experience by women in the pre-maintenance group could have contributed to the lack of significant differences between the two groups. Finally, the study population was recruited from public events focusing on women's health and wellness in which participation in PA was an element. Therefore, the results may not be representative of the population in general or of older or younger women.

\section{Conclusion}

In summary, this study provides evidence that, for some populations, the perceptions of the benefits of PA (including possible weight reduction) and the barriers to PA participation do not differ markedly between novice and experienced PA participants. The majority of the participants believed that nearly all of the benefits and barriers were important. This finding calls into question the effectiveness of developing interventions that focus on benefits and barriers as a strategy for encouraging long-term participation in regular PA. For these individuals, it may be more effective for practitioners to focus on other evidence-based strategies such as promoting social support and increasing self-efficacy. There is strong evidence that counseling individuals to utilize social support strategies such as buddy systems and walking groups or that teach goal-setting and self-monitoring to increase selfefficacy will substantially increase the odds of sustained adherence to a PA program [33].

\section{Acknowledgements}

This work was partially supported by the US Department of Agriculture Supplemental Nutrition Assistance Program Education funding through the Oklahoma Department of Human Services.

\section{References}

[1] Centers for Disease Control and Prevention (2013) Adult Participation in Aerobic and Muscle-Strengthening Physical Activities-United States, 2011. Centers for Disease Control and Prevention, Atlanta, 326-330.

[2] Go, A.S., et al. (2013) Heart Disease and Stroke Statistics-2013 Update: A Report from the American Heart Association. Circulation, 127, e6-e245. http://dx.doi.org/10.1161/CIR.0b013e31828124ad

[3] National Heart Lung and Blood Institute (2009) The Heart Truth for Women. National Institutes of Health, Bethesda.

[4] Ainsworth, B.E., et al. (2003) Personal, Social, and Physical Environmental Correlates of Physical Activity in AfricanAmerican Women in South Carolina. American Journal of Preventive Medicine, 25, 23-29. http://dx.doi.org/10.1016/S0749-3797(03)00161-2

[5] Eyler, A.E., et al. (2002) Correlates of Physical Activity among Women from Diverse Racial/Ethnic Groups. Journal of Women's Health and Gender-Based Medicine, 11, 239-253. http://dx.doi.org/10.1089/152460902753668448

[6] Mathews, A.E., et al. (2010) Older Adults’ Perceived Physical Activity Enablers and Barriers: A Multicultural Perspective. Journal of Aging and Physical Activity, 18, 119.

[7] Wilcox, S., et al. (2002) Perceptions of Physical Activity and Personal Barriers and Enablers in African-American Women. Ethnicity \& Disease, 12, 353.

[8] Carpenter, C.J. (2010) A Meta-Analysis of the Effectiveness of Health Belief Model Variables in Predicting Behavior. Health Communication, 25, 661-669. http://dx.doi.org/10.1080/10410236.2010.521906

[9] Champion, V.L. and Skinner, C.S. (2008) The Health Belief Model. Health Behaviour and Health Education; Theory, Research, and Practice. Jossey-Bass, San Francisco, 45-65.

[10] Prochaska, J. and Di Clemente, C. (1983) Stages and Processes of Self-Change in Smoking: Towards an Integration Model of Change. Journal of Consulting and Clinical Psychology, 51, 390-395. http://dx.doi.org/10.1037/0022-006X.51.3.390

[11] Marcus, B.H. and Owen, N. (1992) Motivational Readiness, Self-Efficacy and Decision-Making for Exercise. Journal of Applied Social Psychology, 22, 3-16. http://dx.doi.org/10.1111/j.1559-1816.1992.tb01518.x 
[12] Lippke, S., Ziegelmann, J. and Schwarzer, R. (2004) Initiation and Maintenance of Physical Exercise: Stage-Specific Effects of a Planning Intervention. Research in Sports Medicine, 12, 221-240. http://dx.doi.org/10.1080/15438620490497567

[13] Sallis, J.F. and Owen, N. (1998) Physical Activity and Behavioral Medicine. In: Sallis, J. and Owen, N., Eds., Behavioral Medicine and Health Psychology, Volume 3, Sage Publications, Thousand Oaks.

[14] Price, A.E., Greer, B.K. and Tucker, A. (2013) Older Black Women’s Experiences Initiating and Maintaining Physical Activity: Implications for Theory and Practice. Journal of Aging and Physical Activity, 21, 348-366.

[15] Pekmezi, D., Marcus, B., Meneses, K., Baskin, M.L., Ard, J.D., Martin, M.Y., et al. (2013) Developing an Intervention to Address Physical Activity Barriers for African-American Women in the Deep South (USA). Women's Health, 9, 301-312. http://dx.doi.org/10.2217/whe.13.20

[16] Juniper, K.C., Oman, R.F., Hamm, R.M. and Kerby, D.S. (2004) The Relationships among Constructs in the Health Belief Model and the Transtheoretical Model among African-American College Women for Physical Activity. American Journal of Health Promotion, 18, 354-357. http://dx.doi.org/10.4278/0890-1171-18.5.354

[17] Marcus, B.H., Pinto, B.M., Simkin, L.R., Audrain, J.E. and Taylor, E.R. (1994) Application of Theoretical Models to Exercise Behavior among Employed Women. American Journal of Health Promotion, 9, 49-55. http://dx.doi.org/10.4278/0890-1171-9.1.49

[18] Oldridge, N.B. and Streiner, D.L. (1990) The Health Belief Model: Predicting Compliance and Dropout in Cardiac Rehabilitation. Medicine \& Science in Sports \& Exercise, 22, 678-683.

[19] Taggart, H.M. and Connor, S.E. (1995) The Relation of Exercise Habits to Health Beliefs and Knowledge about Osteoporosis. Journal of American College Health, 44, 127-130. http://dx.doi.org/10.1080/07448481.1995.9939106

[20] Dishman, R. (1988) Overview. In: Dishman, R.K., Ed., Exercise Adherence: Its Impact on Public Health, Human Kinetics, Champaign, 1-9.

[21] Kaminsky, L.A. and Bonzheim, K.A. (2006) ACSM’s Resource Manual for Guidelines for Exercise Testing and Prescription. Lippincott Williams \& Wilkins, Philadelphia.

[22] DeSalvo, K.B., Bloser, N., Reynolds, K., He, J. and Muntner, P. (2006) Mortality Prediction with a Single General Self-Rated Health Question. Journal of General Internal Medicine, 21, 267-275. http://dx.doi.org/10.1111/j.1525-1497.2005.00291.x

[23] McHorney, C.A., Ware Jr., J.E. and Raczek, A.E. (1993) The MOS 36-Item Short-Form Health Survey (SF-36): II. Psychometric and Clinical Tests of Validity in Measuring Physical and Mental Health Constructs. Medical Care, 31, 247-263. http://dx.doi.org/10.1097/00005650-199303000-00006

[24] Pierannunzi, C., Hu, S.S. and Balluz, L. (2013) A Systematic Review of Publications Assessing Reliability and Validity of the Behavioral Risk Factor Surveillance System (BRFSS), 2004-2011. BMC Medical Research Methodology, 13, 49. http://dx.doi.org/10.1186/1471-2288-13-49

[25] Centers for Disease Control and Prevention (2012) Behavioral Risk Factor Surveillance System. http://www.cdc.gov/brfss/data documentation/index.htm

[26] Fishbein, M. (1995) Developing Effective Behavior Change Interventions: Some Lessons Learned from Behavioral Research. NIDA Research Monograph, 155, 246-261.

[27] Marcus, B.H., Selby, V.C., Niaura, R.S. and Rossi, J.S. (1992) Self-Efficacy and the Stages of Exercise Behavior Change. Research Quarterly for Exercise and Sport, 63, 60-66. http://dx.doi.org/10.1080/02701367.1992.10607557

[28] Schaffer, J. (1995) Multiple Hypothesis Testing. Annual Review of Psychology, 46, 561-584. http://dx.doi.org/10.1146/annurev.ps.46.020195.003021

[29] Janiszewski, P.M. and Ross, R. (2009) The Utility of Physical Activity in the Management of Global Cardiometabolic Risk. Obesity, 17, S3-S14. http://dx.doi.org/10.1038/oby.2009.382

[30] Do Lee, C., Blair, S.N. and Jackson, A.S. (1999) Cardiorespiratory Fitness, Body Composition, and All-Cause and Cardiovascular Disease Mortality in Men. The American Journal of Clinical Nutrition, 69, 373-380.

[31] Wing, R.R., et al. (2007) Fitness, Fatness, and Cardiovascular Risk Factors in Type 2 Diabetes: Look Ahead Study. Medicine and Science in Sports and Exercise, 39, 2107-2116. http://dx.doi.org/10.1249/mss.0b013e31815614cb

[32] Ross, R. and Janiszewski, P.M. (2008) Is Weight Loss the Optimal Target for Obesity-Related Cardiovascular Disease Risk Reduction? Canadian Journal of Cardiology, 24, 25D-31D. http://dx.doi.org/10.1016/S0828-282X(08)71046-8

[33] Kahn, E., Ramsey, L., Brownson, R., Heath, G., Howze, E., Powell, K., et al. (2002) The Effectiveness of Interventions to Increase Physical Activity: A Systematic Review. American Journal of Preventive Medicine, 22, 73-107. http://dx.doi.org/10.1016/S0749-3797(02)00434-8 